\title{
PRÁTICAS PEDAGÓGICAS E OBRIGATORIEDADE DE ENSINO NOS PRIMÓRDIOS DO SÉCULO XX: FUNDAMENTO PARA ANÁLISE DAS POLÍTICAS PÚBLICAS EDUCACIONAIS NA CONTEMPORANEIDADE
}

\section{EDUCATIONAL PROCEDURES AND OBLIGATORINESS IN THE EARLY 20th CENTURY: BASE FOR THE ANALYSIS OF CURRENT PUBLIC EDUCATIONAL POLICIES}

\author{
Jardel Costa Pereira*
}

\begin{abstract}
RESUMO: Com a instalação dos Grupos Escolares no Estado de Minas Gerais a partir da reforma educacional de 1906 instituída pelo governo João Pinheiro, surgiram novos enfrentamentos como a obrigatoriedade escolar. Com o intuito de se evitar a evasão escolar e garantir a frequência dos alunos foram criadas várias práticas pedagógicas. A partir dos escritos de Firmino da Costa Pereira, primeiro diretor do Grupo Escolar de Lavras, cidade do sul de Minas Gerais, procura-se por meio desse artigo, compreender como questões tão emblemáticas na contemporaneidade já se faziam presentes nos primórdios do século XX, analisando as estratégias que foram inventadas para garantir a presença dos alunos nos bancos escolares.
\end{abstract}

Palavras-chave: Grupo Escolar; Obrigatoriedade de ensino; Cultura escolar.

ABSTRACT: Upon the implementation of public school groups in the State of Minas Gerais, after the educational reformulation made by João Pinheiro's government in 1906, new confrontations appeared, such as educational obligatoriness. In order to avoid students' evasion from school and ensure their attendance to classes, several educational procedures were created. Based on the writings of Firmino da Costa Pereira, first principal to Grupo Escolar de Lavras, a city in the South of Minas Gerais, this paper aims at understanding how such complex and current questions were already an issue in the early 20th century, by analyzing the strategies that were created to ensure students would attend classes at school.

Keywords: Public School Groups; Educational Obligatoriness; School culture.

A criação de políticas públicas educacionais com o propósito de garantir a permanência dos alunos na escola, garantindo a obrigatoriedade de ensino e diminuindo a evasão escolar têm sido uma constante na contemporaneidade. Muitos cidadãos brasileiros criticam a aplicação de verba pública para esse fim, esquecendo que esse problema já foi ou está sendo enfrentado por muitos países, e

\footnotetext{
"Doutor em Educação Escolar pela Universidade Estadual Paulista “Júlio de Mesquita Filho" (Unesp)

- Campus de Araraquara. Docente da Universidade do Estado de Minas Gerais (UEMG), vinculado

a grupos de pesquisa na Universidade Federal de Lavras (UFLA - GIEPHE), na Universidade Federal de Minas Gerais (UFMG - GEPHE) e pesquisador da Fundação de Amparo à Pesquisa do Estado de Minas Gerais (FAPEMIG). Contato: jardelcostper@gmail.com
} 
que dele depende a diminuição do número de analfabetos e consequentemente, a formação e a qualificação das crianças e jovens de uma determinada sociedade.

Historicamente o Brasil vem enfrentando esse problema educacional desde os primórdios do século passado, a partir do momento em que a lei da obrigatoriedade de ensino paulatinamente se transformou num axioma a ser defendido.

O primeiro diretor do Grupo Escolar de Lavras, cidade do Sul de Minas Gerais, ao enfrentar esse problema, tratou-o estabelecendo reflexões sobre essa temática.

No boletim Vida Escolar de 15 de julho de 1908, Firmino da Costa Pereira ${ }^{1}$ escreveu um artigo intitulado "Instrucção obrigatória", que apontava situações que demonstraram quão preocupante era, por parte dos professores e do diretor, a infrequência dos alunos, revelando também que Firmino Costa queria mostrar ao novo secretário do Interior, Estevam Leite de Magalhães Pinto, ${ }^{2}$ a atenção que 0 assunto requeria.

O diretor, afirmando que a instrução era obrigatória no Estado e a lei não era cumprida por falta de vagas nas escolas, propôs que nas cidades onde houvesse escola para todas as crianças a obrigatoriedade deveria ser exigida.

O discurso de Firmino Costa em defesa da obrigatoriedade manifesta a finalidade da reforma educacional presente nos ideais republicanos de civilidade: "Ninguem tem direito de ser ignorante, de ficar entravando o progresso do paiz, de viver como bruto, - é preciso instruir-se, com a verdadeira instrucção, que o prepare para a familia e para a pátria." (SECRETARIA DO INTERIOR, SI 2850, 1907)

A infrequência, considerada pelo diretor como atitude irracional, deveria ser banida da sociedade, e um aparato de racionalidade foi montado com a reforma da instrução de 1906, demonstrando a preocupação das autoridades em elevar o nível

\footnotetext{
${ }^{1}$ Firmino da Costa Pereira nasceu em Niterói, Rio de Janeiro, em 1869, onde sua mãe se encontrava para um tratamento de saúde. Em Lavras, trabalhava no comércio do pai e após ter feito o Curso Secundário se tornou professor de Português no Curso Secundário do Instituto Presbiteriano Gammon. Devido ao seu autodidatismo, a sua influência social e aos parentes políticos e influentes como Francisco Salles e Pedro Salles, Firmino foi escolhido para ser o primeiro diretor do Grupo Escolar de Lavras, inaugurado aos 13 de maio de 1907. Após 18 anos na direção do Grupo Escolar de Lavras, Firmino Costa foi convidado a ser o reitor do Internato do Ginásio Mineiro, em Barbacena, em 1925. Após um curto prazo de tempo, ele se tornou diretor técnico do Curso de Aplicação da Escola Normal de Belo Horizonte.

2 Com a morte do presidente do Estado, João Pinheiro, em 25 de outubro de 1908, o secretário do Interior, Carvalho Britto, deixa o cargo, vindo a substituí-lo Estevam Leite de Magalhães Pinto, no mandato do novo presidente do Estado, Wenceslau Braz Pereira Gomes.
} 
de conhecimento da população e, consequentemente, ter cidadãos instruídos e civilizados.

Delfim Moreira, no cargo de Secretário do Interior no ano de 1910, ao apresentar ao Presidente do Estado Julio Bueno Brandão um relatório sobre a instrução primária, refutou a não obrigatoriedade da frequência no ensino primário pela reforma de 1906, dizendo ser cabível essa medida nos países onde todos já fossem educados e que as famílias valorizassem o ensino, demonstrando que isso não acontecia ainda no Brasil.

Em 1912, Firmino Costa voltou a escrever sobre a obrigatoriedade da frequência do aluno na escola. Em seu parecer, a organização criada para o ensino público primário tinha uma falha, pois, além de o número de alunos matriculados ser maior que os frequentes, o número de aprovados no último ano era pequeno, quando não saíam do Grupo semi- analfabetos.

Mediante essa situação, o diretor via a necessidade urgente de encontrar "meios para tornar obrigatório o ensino." (COSTA, p. 18, 1913) O primeiro instrumento por ele apresentado para aumentar a frequência nas escolas foi a criação de um cargo de professora adjunta, que seria uma representante da escola que visitaria as famílias dos alunos, com o intuito de uma "propaganda a favor da frequência." (COSTA, p. 18, 1913) Essa sua ideia era originária do conceito que ele tinha da escola como "auxiliar da família, a cujos filhos vem prestar sua cooperação educativa" (COSTA, p. 18, 1913), sendo que uma não devia viver separada da outra.

O segundo instrumento seria a instituição de uma "polícia escolar", que em regime experimental poderia ser até um guarda civil, que deteria em flagrante os alunos que ficassem vadiando pelas ruas da cidade ao invés de irem para a escola.

Persistindo na ideia de criação de uma guarda escolar, Firmino Costa, no relatório de 1916, retoma esse assunto, apresentando à Secretaria a necessidade de combater a influência "quase sempre deseducativa" da rua sobre as crianças, explicando como funcionaria esse policiamento:

Esta policia, composta de alumnos sob as ordens do director do grupo, sem onus para o Estado, seria a vigilante protectora da frequencia, não consentindo que nas horas de aula permanecessem alumnos na rua. Aquelle que fosse ahi encontrado teria de comparecer á escola, dando se aos paes conhecimento do facto. (COSTA, p. 42, 1916) 
Inscrevendo-se na escola, a cidade, no parecer do diretor, é percebida como experiência de medo, ameaçando a formação que os professores davam aos seus alunos. Em contrapartida, o espaço urbano, para Firmino Costa, poderia ser utilizado para educar, criando pontos de recreação nas praças públicas, onde as crianças "[...] passariam seus folguedos em logares mais hygienicos, não incommodariam o transito, poderiam ser facilmente fiscalizados e teriam uma nova escola, ao ar livre, onde certamente conseguiriam pôr em pratica o sefl-government." (COSTA, 1916, p. 43)

Com Faria Filho, ao analisar a escola e a cidade, percebe que "a cidade vai definindo seu lugar específico no espaço da escola - no sentido que vai impondo à escola uma maneira específica de conceber e ordenar as relações sociais." (FARIA FILHO, 2002, p. 9)

Nesse contexto e ilustrando o raciocínio desse historiador da educação, encaixa-se um terceiro instrumento contra a infrequência, que Firmino Costa expôs relacionando a ajuda financeira que o Grupo Escolar daria às crianças carentes para garantir-Ihes a presença na escola:

Estes meios de compellir os alumnos á frequencia completar-se-iam não só com a acção beneficente da caixa escolar, provendo do necessario as creanças pobres, mas tambem com a execução das disposições respectivas já consignadas no regulamento geral do ensino. (COSTA, 1913, p. 18)

Algumas medidas foram tomadas para que o aluno que abandonou a escola retornasse, independentemente do motivo.

\section{EM BUSCA DE ALUNOS DESERTORES}

Firmino Costa registrou, no relatório de 1907, publicado no boletim Vida Escolar aos 15 de julho, o procedimento que utilizou com o objetivo de aumentar a frequência:

Passei depois a me occupar da frequencia, dirigindo-me nas aulas a cada um dos alumnos, elogiando os que foram assiduos, excitando os outros, presentes na occasião, a imitarem os primeiros, 
incumbindo a alguns de convidar os faltosos a comparecerem. Taes meios vão surtindo bons resultados, esperando eu que no actual semestre será muito regular a frequencia. (VIDA ESCOLAR, p. 1, 15 jul. 1907)

Passados oito meses depois da instalação do Grupo Escolar, no período de férias, de 7 a 21 de janeiro, reunidos na escola o diretor e os professores, conforme o regulamento, iniciou-se a matrícula para 1908.

Mas, em vez de ficarem esperando que o aluno e seus familiares viessem ao Grupo, eles resolveram ir à casa do aluno, fazendo um recenseamento escolar. No mês de abril, no boletim Vida Escolar, ficou registrado, na terceira pessoa do plural, como esse arrolamento foi feito:

Para este fim tivemos que percorrer todas as casas, onde conversámos com os chefes de familia sobre o grande valor do Grupo, sobre as vantagens da reforma do ensino, sobre o dever de preparar melhor futuro para os pequenos lavrenses de hoje. (VIDA ESCOLAR, 1ำ abr. 1908)

O Grupo Escolar precisava tornar-se visível, incutido na memória da cidade, para que fosse valorizado, para que o povo, especificamente os pais de família, confiassem no trabalho ali realizado. Por isso, a frequência escolar dependia também do auxílio dos pais dos alunos, daí o apelo para que não deixassem seus filhos faltar às aulas sem motivo.

Por intermédio desse recenseamento, puderam conhecer a família dos alunos, tomar conhecimento do que lhes faltava para melhor educá-los.

Mas, em um artigo publicado no boletim Vida Escolar de 15 de julho de 1908, três meses depois do acontecido, houve a narração de alguns fatos que indicavam terem acontecido durante a visita realizada às famílias dos alunos do Grupo, e que chamam a atenção, pelo significado e sentido de resistência presente no cotidiano da vida familiar:

Casos verídicos Estamos presente, ainda de pé.

A mãe - Meu menino não se tem adeantado nada no Grupo.

O menino - O sr. quer assentar-se? Num dia santo.

- Você veio hoje tarde!

- Eu vim sem mamãe saber, ella não queria. Porque não voltaste para o Grupo? 
- Eu bem queria, foi papae que não deixou. Hermilio, você já ia tão bem no Grupo e foi sair de lá, porque?

- Papae me poz noutra escola.

- Você então não gosta do Grupo?

- Eu, eu gosto muito, mas papae não quis que eu continuasse. Qual! No Grupo meu filho vae aprender maus costumes com os meninos do povo.

- Eu o estou vendo brincar em sua casa com os taes meninos.

- É, mas no Grupo não serve.

Pois é engano da sra. julgar seu filho melhor que os do povo. No Grupo, minha sra., não são apenas os meninos de familias elevadas os que se distinguem no procedimento e no aproveitamento. Dos filhos do povo há tambem muitos que figuram nos boletins com elevadas notas. Os bons sentimentos e os dotes da intelligencia tambem se encontram, minha sra., nas familias humildes. Ponha seu filho entre os da idade delle e não o crie na redoma, tornando-o desde pequeno um pocinho de soberba. (VIDA ESCOLAR, p. 4, 15 jul. 1908)

A construção e a propaganda de uma nova cultura escolar estavam sendo, pouco a pouco, incutidas no cotidiano da vida da população. No primeiro exemplo, a palavra "Grupo" já faz parte do vocabulário da mãe do menino e no terceiro percebese que o próprio aluno dá o seu testemunho de que gostava muito de estudar no Grupo, mas, por forças maiores teve que sair.

Os alunos que haviam abandonado os estudos eram chamados de "desertores": os "coitadinhos", os infelizes e desventurados que viviam pelas ruas preferindo "a indifferença dos transeuntes" ao "zelo dos professores", desprezando a educação para se tornarem escravos da ignorância.

O convite do diretor aos pais para visitarem o Grupo Escolar, conhecê-lo e ver onde seus filhos passavam boa parte do dia era insistente:

[...] Quem quer que seja não fique acanhado de visitar o Grupo, pois elle pertence ao povo, elle é principalmente dos meninos de Lavras. Teremos sincero prazer em conversar com os paes e mães de família sobre os seus pequenos, cujo futuro tambem nos interessa. Aos pobres, ainda mais que aos outros, precisamos de dizer algumas palavras a bem de seus filhos. E não considerem a visita ao Grupo como um simples passeio ou perda de tempo, antes como cumprimento de um dever, como serviço que prestam aos filhos. (VIDA ESCOLAR, p. 1, 1ํs. 1907)

É com esse teor, chamando a atenção dos pais, que o artigo publicado em 15 de outubro de 1908, no boletim Vida Escolar apresentou quem eram os desertores, 
bem como a indignação de Firmino Costa ao vê-los abandonados nas ruas da cidade, quando deveriam estar na escola cultivando a inteligência e formando o caráter.

Em seu parecer, sem instrução as crianças seriam inúteis e até perigosas para a sociedade. Era difícil ao diretor aceitar que a instrução, não tinha nenhum valor para as crianças e para seus familiares.

As campanhas para o aumento da frequência eram realizadas especialmente para os alunos pobres, pois pobreza significava atraso, irracionalidade, falta de educação, e a escola oferecia a oportunidade para que eles fossem educados, tornando-os úteis em sociedade. Uma nova cultura escolar é construída, tendo como base a civilidade e o progresso, necessários "para a organização de uma sociedade racionalizada, constituída por indivíduos independentes material e mentalmente." (VEIGA; FARIA FILHO, 1997, p. 204)

Há certa racionalidade nos exemplos que foram citados nesse artigo e que demostram as proibições e controles do Estado sobre os indivíduos: "A bem da moralidade não consente o Estado que alguem ande despido pelas ruas; para garantia da sociedade não permite elle o uso de certas armas; como repressão do vicio elle prohibe os jogos de azar." (VIDA ESCOLAR, p. 2, 15 out. 1908)

Firmino Costa utilizou esses exemplos para expor que o abandono escolar também prejudicava o bem social e era responsável pelo aumento de pessoas analfabetas, por isso deveria ser combatido e proibido por lei.

Utilizando a palavra "desertores" com sentido daquele que comete um crime ao abandonar o exército, símbolo do serviço máximo de entrega e amor à pátria, o diretor considerava um ato condenável abandonar os estudos que o Estado oferecia gratuitamente nos Grupos Escolares, concluindo com o seguinte recado ao Governo:

[...] Sem forças numerosas e disciplinadas a Republica não poderá impor-se ao respeito das outras nações; sem instruç̧ão generalizada e methodica ella não conseguirá acompanhar a marcha da civilização. Assim persuadido, eu renovo ao Governo o meu pedido de tornar-se effectiva a obrigatoriedade da instrucção primaria.

(VIDA ESCOLAR, p. 2, 15 out. 1908)

A força de uma nação republicana constava de um exército numeroso e de um povo instruído, o que garantiria uma caminhada rumo à civilização. Um estado 
de constante adiantamento rumo ao progresso, acompanhado de um nível elevado de cultura social.

Comungando e propagando os ideais republicanos de civilidade, o diretor, por meio desses seus pensamentos, deixou transparecer, também, a escola que ele se propunha a construir. Para Justino Magalhães, encarar a identidade de uma instituição educativa é considerar a "escola como um agente de produção, um meio pedagógico e didactico necessário que traz um contributo insubstituível para a construção social”.

Para atrair e garantir a frequência diária dos alunos no Grupo Escolar de Lavras, foram criados alguns recursos pedagógicos e didáticos, como veremos a seguir.

\section{CONCILIANDO A LEI COM O COSTUME: O TEMPO ESCOLAR}

Uma questão que teve de passar pelo crivo da racionalidade foi o horário de início das aulas: a abertura das aulas às dez horas da manhã era o horário do almoço dos alunos, o que atrapalhava a pontualidade e a frequência. Firmino Costa, no boletim Vida Escolar de $1^{\circ}$ de agosto de 1907, refletindo sobre esse inconveniente, escreveu ${ }^{3}$ :

Nada mais fácil que antecipar o almoço, poderão dizer-nos. Não é tal. Alem de ser sempre difficil mudar habitos antigos, viria isso alterar outras occupações relacionadas com a hora da refeição. Acontece, pois, que o menino, querendo ser pontual, ficará quase sempre sem almoço, ou almoçará ás pressas, o que é nocivo á saude. (VIDA ESCOLAR, p. 1, 1ํag. 1907)

A solução, para Firmino Costa, estaria em mudar o horário do início das aulas para as onze horas, como acontecia em São Paulo, "conciliando a lei com o costume", pois a lei deveria combater os costumes prejudiciais à sociedade.

Uma nova racionalidade passa a configurar outra visão na utilização do tempo e do espaço escolar que, medidos, cronometrados e controlados, deveriam demonstrar o caráter de modernidade que se queria imprimir a partir da Reforma

\footnotetext{
${ }^{3}$ Em seu primeiro relatório de 29 de janeiro de 1908, Firmino Costa reapresentou, com as mesmas palavras, a necessidade que via na mudança do horário do início das aulas.
} 
João Pinheiro. Firmino Costa compartilhava esses ideais, defendendo o despontar de uma nova escola que, dirigida por princípios racionais e úteis, garantiria uma boa frequência:

\begin{abstract}
A escola [...] firmada no amor e na justiça para com os alumnos, funccionando em hora apropriada, respirando alegria e conforto, por certo attrahirá grande frequencia. E em certos dias terão os meninos razões especiaes para comparecer, como no dia do exame mensal, no da entrega dos boletins, no da distribuição de cartões de boas notas, no da apuração dos mesmos cartões, no dia deste ou daquelle brinquedo, etc.
\end{abstract}

(VIDA ESCOLAR, p. 1, 1ํ ag. 1907)

Firmino Costa, com atitudes racionais para o tempo escolar, sugeria que 0 período de férias, de feriados e dias santos fosse preenchido com outras atividades:

\begin{abstract}
Férias
Em vez de férias longas, como há, que são muito prejudiciaes ao ensino e desnecessárias aos alumnos do curso primário, todos em geral residentes na sede escolar, eu estou que seria preferível houvesse quatro feriados durante o anno - feriados do Natal e Anno Bom, da Semana Santa, de S. João e de S. Pedro, da Independência Nacional. E assim também dever-se-iam considerar feriados os dias santos, que isso apenas importa em reconhecer um facto. Entretanto não approvo os feriados de quintas-feiras, que sem razão alguma vieram perturbar o ensino. Para pôr mais em evidencia a quantidade de feriados nas escolas publicas, basta attender a que neste anno, si descontássemos dias santos, quintas-feiras, domingos e dias de festa nacional, haveria 194 dias de aula contra 170 dias feriados! (MINAS GERAES, 29 dez. 1909)
\end{abstract}

Prescrevendo os horários do tempo escolar que foram impostos aos professores, diretores, alunos e até mesmo às famílias pelos regulamentos de ensino, Faria Filho analisa que "esse processo ocorre no interior de um movimento social de racionalização do tempo, próprio às relações capitalistas que se estabeleciam". (FARIA FILHO, 2000, p. 71)

Mas essa racionalização não aconteceu de uma hora para outra, sendo que uma reforma concreta voltada para o 'tempo' que se estendia desde a idade certa para iniciar o ensino primário, a extinção da quinta-feira como feriado e à mudança do horário de início das aulas, aconteceu somente em 1910, tendo sido anunciada 
pelo Secretário do Interior Estevão Leite de Magalhães Pinto, em um relatório apresentado ao Presidente do Estado, Wenceslau Braz Pereira Gomes.

Se essa racionalização temporal era aplicada para organizar o início das matrículas, o período de férias, a data dos exames finais e o término do ano letivo, escapava ao seu domínio e controle como os pais e os alunos viam e utilizavam esse tempo. Conscientizando e chamando a atenção, em um artigo denominado "Aviso aos paes", sem autoria e publicado no boletim Vida Escolar, levantou o problema da pontualidade que, se não utilizada racionalmente, causaria muitos transtornos:

A impontualidade é um mal, que precisa de ser combatito entre nós; ella desorganiza por completo todo o trabalho; ella causa prejuizos e desgostos aos que chegam tarde e aos que ficam esperando; ella é uma grosseria que todos devemos evitar.

Ajudem-nos, pois, os paes, mandando seus filhos para o Grupo á hora marcada e não deixando assim que elles percam tempo tão precioso qual o do estudo. (VIDA ESCOLAR, p. 1, 1ำ maio 1908)

Não era permitida a entrada de alunos que chegassem depois do horário marcado para $o$ início das aulas e, para ser considerada legal sua frequência mensal, ele deveria ter 19 presenças, podendo ter de 11 a 12 faltas, fora os dias santos e feriados. Esses dados vinham no boletim do aluno, que recebia nota de frequência, cabendo aos pais verificar se seus filhos alcançaram o número legal de dias. Portanto, das famílias dependiam também a regulamentação do tempo e, consequentemente, a ordem no espaço escolar. Tempo e espaço, intrinsecamente ligados, contavam com a ajuda dos pais para seu funcionamento:

[...] O que não póde ser é o pae deixar de acompanhar a educação do filho: é esse um de seus primeiros deveres. Amar ao filho não é só dar-lhe de comer e de vestir, não é só tratar delle nas doenças, é também preparar-Ihe a intelligencia para as luctas da vida, seguindo com todo interesse e constancia o trabalho do menino na escola. (VIDA ESCOLAR, p. 1, 1 maio 1908)

Parceiras na educação e proteção da infância, escola e família deveriam trabalhar unidas para preservar o que era de direito e próprio do mundo das crianças: estudar e brincar. Conciliando esses dois tempos, na sala de aula e no pátio de recreio, conquistando os alunos, e ao mesmo tempo formando-os. 
No relatório de 1913, num item específico denominado "Publicações", Firmino Costa escreveu ao secretário do Interior apresentando a publicação para uso das escolas de "dois trabalhos didacticos", um referente a uma coleção de cartões escolares, "Colecção F.C.", e o outro, o seu primeiro livro a ser publicado pela imprensa oficial do Governo Estadual, O Ensino Popular, onde o diretor escreveu que muitos pais tinham pressa em ver os seus filhos já formados ou trabalhando.

O diretor, dividindo em duas partes essa sua introdução, primeiramente tratou da parte referente ao trabalho infantil, que a seu ver significava uma resistência à nova cultura escolar, sendo prejudicial à frequência dos alunos na escola. Utilizando o serviço das crianças, os chefes de família matriculavam seus filhos ou protegidos, mas não os deixavam frequentar regularmente a escola.

Em um dos escritos da parte do livro O Ensino Popular denominada $A$ pressa, o diretor apresentou tempos distintos e próprios da idade: tempo para as ocupações escolares, para brincar e ainda ajudar em algum serviço em casa. Mas sacrificar todo o tempo da criança por um trabalho remunerado, trocando "a escola por alguns nickeis", satisfazendo o egoísmo dos pais, para Firmino Costa era formar trabalhadores medíocres e ignorantes.

Para Firmino Costa, era condenável aceitar a pressa de alguns pais de tirar seus filhos da escola antes que concluíssem o ensino primário, pois estariam sacrificando o futuro da própria família. Ele não via nenhuma utilidade no trabalho de uma criança ignorante, que recebia qualquer pagamento pelo seu serviço e ainda mais o entregaria todinho para alguém: "O trabalho é nobilíssimo, ninguem contesta, mas o estudo é tambem um trabalho, e é o trabalho do menino em edade escolar." (COSTA, 1913, p. 79)

Para o controle e a contagem do tempo, o relógio passa a significar um objeto de fiscalização da pontualidade dos alunos, chegando mesmo a ser sugerido pelo diretor, em seu relatório de 1917, que fosse colocado "um regulador publico no predio escolar, cessando, por esta fórma, as desculpas baseadas nas differenças dos relógios", (MINAS GERAES, 8 fev. 1918, p. 2) necessidade que poderia estar surgindo nas situações de tentativas de enganar o porteiro e burlar o horário. 


\section{“A ESCOLA MODERNA DEVE SER CARINHOSA"}

A passagem de uma escola na qual era permitido castigar fisicamente os alunos que não tivessem bom comportamento ou até mesmo um bom desempenho escolar para outra em que deveria prevalecer a educação das crianças fundamentados no respeito, seria importante para atrair as crianças e manter a frequência.

Os professores deveriam, a partir da reforma de 1906, conquistar o prestígio perante os pais dos alunos, seja pela competência, seja também pelo carinho, fazendo da escola um prolongamento do próprio lar. (MINAS GERAES. Regulamento da instrucção primaria e normal do Estado de Minas, 1906, p. 6)

Defendendo esse argumento, Susanna Alvarenga, professora de uma turma da oitava escola do sexo masculino, escreveu no boletim Vida Escolar de 15 de agosto de 1908 um artigo denominado "O carinho na Escola", recordando a época em que os alunos eram castigados e viam os professores "com terror e aversão", o que contribuía para faltarem à escola, pois eles não queriam estar em "contacto com aquelles que os maltratavam".

A seu ver, houve uma mudança na maneira de educar os alunos, que passaram a ser tratados com "carinho e delicadeza", sentindo prazer em frequentar as aulas, aprendendo mais, pois não tinham receio de pedir uma explicação, pois eram atendidos pelos professores com interesse e boa vontade.

Procurando demonstrar que a escola era uma extensão do próprio lar do aluno, Susanna Alvarenga fez a seguinte abordagem:

O menino que em casa está habituado á doçura, chega á escola, encontra o mesmo trato, affeiçôa-se ao mestre e acaba por devotarIhe sua inteira estima. Aquelle que, maltratado pelo pae, recebe carinho na escola, da mesma maneira que o outro ou mais que elle preferirá passar todo o tempo nesse logar de prazer a regressar ao lar. (VIDA ESCOLAR, p. 2, 15 de ago. 1908)

Com atitudes de carinho por parte dos professores convencidos de sua missão, as escolas transbordariam de crianças com rostos alegres e cheios de gratidão pelo bem recebido, concluiu a professora, mostrando uma prática pedagógica que certamente colocava em uso com seus alunos em sala de aula. 


\section{REALÇANDO OS MÉRITOS DOS ALUNOS: O PRÊMIO COMO DISTINTIVO DE EDUCAÇÃO}

Somente um artigo do Regimento Interno dos Grupos Escolares prescreve como seria o procedimento de professores e diretores sobre os prêmios escolares: "Art. 63. O director, de accordo com os professores, determinará o processo de prêmios de animação aos alumnos, preferindo o que mais vantagens offerecer ao aproveitamento de ensino e comportamento". (REGIMENTO interno dos grupos escolares e escolas isoladas do Estado de Minas, 1908, p. 18)

Numa ação conjunta com os professores, pois eram eles que lidavam diretamente com os alunos e tinham conhecimento do que acontecia nas salas de aula, o diretor deveria instituir premiações que destacassem os melhores alunos.

Prescrevia o regulamento que, para a seleção desses alunos, deveriam ser levados em consideração dois itens: melhor comportamento e rendimento nos estudos. Mas Firmino Costa acrescentou mais um - a freqüência - ao apresentar, no boletim Vida Escolar, de $1^{\circ}$ de julho de 1907 , quais seriam os prêmios.

Primeiramente o diretor preocupou-se em justificar o motivo da instituição desses prêmios, escrevendo que a criança, da mesma maneira que o adulto, gostava de ver o seu trabalho apreciado:

[...] Este sentimento de amor proprio, que todos possuimos em maior ou menor grau, deve o professor comprehendel-o e aproveital-o, a bem de transfundir nos alumnos o enthusiasmo pelo estudo. Como em outros emprehendimentos da vida, tambem nos trabalhos escolares o enthusiasmo póde levar de vencida não pequenas difficuldades, fazendo despertar energias, que sem elle talvez viessem a ficar perdidas. E, mantendo animação nos trabalhos da escola, mais facil será ao professor fazer observar entre os disicipulos o necessario espirito de ordem. (VIDA ESCOLAR, p. 1, 1ํㅡㄴ jul. 1907)

Explicando os três itens de referência, melhor comportamento, rendimento nos estudos e freqüência, Firmino Costa considerava o aluno infreqüente um rebelde que não queria cumprir suas obrigações; a medição do rendimento dos alunos deveria visar mais ao desenvolvimento da inteligência do que "à habilidade de decorar fórmulas e regras". Já o procedimento, além de incluir um bom 
comportamento na escola, estendia-se também à higiene, ao cuidado que a criança deveria ter com seu corpo - unhas cortadas, cabelos penteados e orelhas limpas - e com suas roupas - sem rasgos e limpas.

As normas disciplinares com prêmios e penas foram caracterizadas por Firmino Costa, como um rigoroso "systema racional de disciplina." (VIDA ESCOLAR, p. $1,1^{\circ}$ jul. 1907)

No entendimento de FARIA FILHO, o processo de racionalização inicia-se na criação da escola brasileira, que pretendia ser moderna, sendo que "a escola não apenas criou ou readaptou teorias e métodos de organização e controle adventícios, mas criou verdadeiramente novas racionalidades, sensibilidades, temporalidades, conhecimentos, dentre outros, que foram "impostos ao conjunto do social". (FARIA FILHO, 2000, p. 37) Essa racionalidade deveria ser estendida ao aprendizado e à freqüência do aluno, ambos relacionados e essenciais à assiduidade ou freqüência.

Com apenas dois meses de início das atividades do Grupo Escolar, os prêmios $^{4}$ foram apresentados como recurso essencial para garantir a freqüência e a disciplina. Como forma de estímulo e de disciplina, esses prêmios foram instituídos de acordo com a reforma João Pinheiro, que incentivava a adoção de técnicas disciplinares modernas em substituição aos castigos físicos.

Vago, ao referir-se à instituição de prêmios pelas diretoras dos Grupos Escolares de Belo Horizonte, cita-os a partir do regulamento do ensino de 1911, que os considerou "como meios disciplinares secundários": "instituição do quadro de honra; [...] cartões de frequencia e bom ponto; [...] distribuição mensal de um ‘premio' em cada sala ao aluno que mais se distinguir”. (VAGO, 2002, p. 133-134)

Outro tipo de recompensa criada e que não aparece nos exemplos de prêmios instituídos em outros Grupos Escolares de Belo Horizonte e do Estado, refere-se aos de valor pecuniário. Esse prêmio foi citado no boletim Vida Escolar de 1ํ de maio de 1908 e instituído na visita que o secretário do Interior, Carvalho Brito, fizera ao Grupo Escolar, no dia 19 de abril do mesmo ano. Os prêmios recebiam nomes de pessoas ilustres da comunidade, consideradas símbolo de civismo;

\footnotetext{
${ }^{4}$ Analisando a expressão do diretor pronunciada no futuro - "Vejamos agora quaes os premios a instituir" - deparamos com duas margens de interpretação: a primeira, que esses prêmios ainda seriam instituídos no Grupo Escolar de Lavras; e a segunda, mais consistente, que ele instituiu os vários tipos de prêmios para que fossem utilizados também por outros Grupos Escolares.
} 
percebe-se, também, uma boa convivência entre os fundadores e doadores das premiações, que, às vezes, davam o nome do próprio colega ao título do prêmio.

Os instituidores desses prêmios escolares mandavam espontaneamente suas contribuições ao Grupo Escolar, mas o prêmio "Francisco Sales" despertou a atenção, por ser a própria Secretaria do Interior que mandava o seu pagamento. Esse prêmio foi formado a partir de juros de apólices da Coletoria do Estado, sendo perpétuo, no valor de $125 \$ 000$ que seriam enviados a um aluno do Grupo Escolar de Lavras e a outro do Instituto João Pinheiro, ${ }^{5}$ em Belo Horizonte, tendo como fundadores Antônio Carlos Ribeiro de Andrade e outros. ${ }^{6}$ Muitas foram as vezes que Firmino Costa enviou ofícios à Secretaria do Interior cobrando o envio do valor do prêmio "Francisco Sales".

Muitos outros prêmios foram criados, e a maioria vinha acompanhada das intenções de seus fundadores": "A exma. sra. d. Anna Isabel da Costa Pereira, digna esposa de nosso amigo sr. Costa Pereira, de Bello Horizonte, instituiu um premio denominado D. Guilhermina Gammon para o alumnos do Grupo, que mais sobresahir no estudo de geographia, de que era a finada d. Guilhermina eximia professora." (VIDA ESCOLAR, p. 2, 1ำ set. 1908)

Mas as intenções de Gustavo Penna, um lavrense residente em Belo Horizonte que instituiu o prêmio de uma medalha de ouro, denominado Dr. Augusto Silva, sobressaíram entre os demais:

Propositalmente excluo o que tiver demonstrado mais intelligencia, porque esta é um dom natural, tão natural como a plumagem dos passaros, e consequencia, quasi sempre, de uma fatalidade atavica. Sempre achei de irracional crueldade humilhar-se a uma creança por ser curta de intelligencia. Mas, a assiduidade e o exemplar

5 Instituto criado em 1909 com o objetivo de cuidar das crianças abandonadas. Para maiores informações confira FARIA FILHO. República, trabalho e educação: a experiência do Instituto João Pinheiro 1909/1934. Editora da Universidade São Francisco, 2001.

${ }^{6}$ Antônio Carlos Ribeiro de Andrada (promotor, magistrado e professor, natural de Barbacena MG) foi governador do Estado de Minas Gerais de 1926 a 1930. O artigo cita que ele e alguns companheiros, durante um banquete oferecido ao Dr. Francisco Salles, senador federal e primo de Firmino Costa, instituíram esses dois prêmios. (Cf. Jornal FOLHA DE LAVRAS, p. 1, 26 mar. 1909)

7 A maioria dos benfeitores queria contribuir com a educação popular, revelando o valor social da educação. As doações eram variadas, e muitas delas não se transformavam em prêmios, como doação de dinheiro para a compra de uniformes para os alunos pobres; os médicos e alguns professores que iam voluntariamente prestar seus serviços aos alunos; remédios para alunos doentes; madeiras para as oficinas de marceneiro; doação de livros para a biblioteca; de objetos para o museu; de máquina de escrever; de telefone sem ônus para o Estado. 
comportamento revelam um esforço, e esse merece ser sempre estimulado. (VIDA ESCOLAR, p. 1-2, 15 set. 1908)

Alguns premiadores reforçavam a intenção de coroar os que mais se destacavam em notas, realçando uma possível desigualdade entre os capazes e os incapazes. Gustavo Penna, em outra direção, igualava todos os alunos como possuidores de uma mesma faculdade: a inteligência. Instituiu o prêmio aos que demonstrassem maior esforço, maior boa vontade, capacidade que não estava ligada a fatores que proporcionariam o destaque de um aluno sobre os demais, como o nível socioeconômico, que sobressaía numa população escolar em que os pobres eram a maioria.

O pensamento de Gustavo Pena parecia estar de acordo com os critérios de avaliação utilizados pelos professores, sendo que um "boletim escolar" de 1907, da aluna "Umbelina de Assis", do segundo ano da terceira escola do sexo feminino, apresentava aos pais os requisitos que eram utilizados para avaliar os alunos, como o "procedimento", "o comportamento" e as "faltas" que eram avaliadas e recebiam notas como se fossem uma "matéria" que estava sendo dada. A nota máxima que o aluno poderia atingir era 10, mas o boletim registrou para o item "comportamento" uma média variável entre 14 até 26 , podendo-se deduzir que o peso maior das notas recaia sobre o "comportamento", sendo um requisito importante a ser observado.

De outro lado, no parecer de Souza, a força simbólica de uma cultura escolar, construída numa base de igualdade, é demonstrada na premiação desses alunos mais inteligentes, que eram destacados na sua individualidade, revelando, ao mesmo tempo, um universo que reproduzia as desigualdades sociais:

É sabido que a República não instaurou no Brasil uma sociedade democrática e a cidadania de fato. Ao contrário, o liberalismo adquiriu no Brasil um caráter de consagração das desigualdades (Carvalho, 1987; Adorno, 1988). Dessa forma, numa sociedade marcada por forte estrutura hierárquica e por grandes desigualdades sociais, explica-se por que a ideologia liberal do mérito tenha sido tão valorizada. (SOUZA, 1998, p. 247)

Expostas todas as finalidades que se pretendiam atingir com os prêmios escolares, a partir de 1911, eles se tornaram mais abrangentes, havendo um 
intercâmbio entre o Grupo Escolar de Lavras e as escolas particulares, que passaram a oferecer lugares aos alunos que se destacavam.

Uma especificidade dos Grupos Escolares foi a criação das "caixas escolares", que procurava fornecer aos alunos carentes recursos para que tivessem condições materiais para frequentar as aulas.

\section{"O ANJO TUTELAR DA EDUCAÇÃO DOS MENINOS POBRES": A CAIXA ESCOLAR}

Firmino Costa fez referência ao regulamento geral do ensino ao referir-se à Caixa Escolar, mas no documento oficial denominado "Regulamento da Instrucção Primaria e Normal do Estado de Minas" nada se encontra sobre esse tema.

Somente o "Regimento Interno dos Grupos e Escolas Isoladas" é que apresenta um capítulo dedicado à Caixa Escolar. O primeiro artigo desse item prescrevia o seguinte:

Art. 58. A cargo do director e sob sua exclusiva responsabilidade poderá ser creada uma CAIXA ESCOLAR, para occorrer ás pequenas despesas do estabelecimento, de expediente e auxílios aos alumnos pobres.Paragrapho único. A sua escripturação, simples e clara, deve ser feita em livro especial com debito e credito, extrahindo-se em cada mez o saldo, que será communicado ao governo com todos os esclarecimentos da receita e despesas mensaes.

(MINAS GERAES, Regimento interno dos grupos e escolas isoladas do Estado de Minas, 1908, p. 17)

A arrecadação de dinheiro consistiria no valor das gratificações que os professores faltosos sem justificativa ou de licenças não recebiam, das doações feitas por pessoas da comunidade, dos vários produtos confeccionados pelos alunos, das festas populares conhecidas por Quermesses ou Tômbolas e de outros meios ou recursos convenientes autorizados pelo governo.

No primeiro semestre de funcionamento do Grupo Escolar, no periódico Vida Escolar de 15 de novembro de 1907, ficou registrada a primeira doação:

O generoso cidadão sr. Custodio de Souza Pinto, um dos lavradores mais adeantados deste districto, trouce-nos espontaneamente 0 donativo de cincoenta mil réis afim de ser applicados na compra de uniformes para alumnos pobres deste estabelecimento.Muito 
agradecemos esse donativo ao philantropico cidadão que está sempre prompto para auxiliar todos os emprehendimentos uteis deste logar.

Se o "Regimento" prescrevia que cabia ao diretor de um Grupo Escolar a criação da Caixa Escolar, subentendendo-se a invenção de estruturas de arrecadamento de fundos para ajuda aos alunos pobres, no começo de 1908, Firmino Costa apresentava suas primeiras idéias sobre esse assunto:

\footnotetext{
EM PROL DA INSTRUCÇÃO

$[\ldots]$

Formemos, pois, uma associação, cujos membros se compromettam solemnemente a trabalhar com a palavra e com o exemplo em prol da instrucção. Só com essas duas armas - a palavra e o exemplo, attingiremos o nosso fim. Nenhum socio poderá combater o ensino, antes cumprir-lhe-á obrigação de defendel-o sempre; nenhum socio poderá deixar os seus pequenos, sejam filhos, protegidos ou creados, sem frequentarem a escola.

Homens e senhoras farão parte da associação, que não exigirá dos socios nem joias e nem mensalidades, e somente receberá para a Caixa Escolar do Grupo o que espontaneamente quizerem dar.

[...]. (VIDA ESCOLAR, p. 2, 15 jan. 1908)
}

Lembrando que sempre foi do interesse da comunidade ajudar a instrução pública primária da cidade, citando a "Associação Propagadora da Instrucção", responsável pela criação da Casa de Instrução, prédio que foi transformado em Grupo Escolar, Firmino Costa convocou diversas autoridades civis e políticas a tomar a iniciativa de criação da Caixa Escolar, tornando-se ele mesmo um contribuinte com $10 \$ 000$ mensais.

A atuação da cidade nas necessidades financeiras da escola se constrói numa relação de responsabilidades que precisavam ser divididas. Com formas bastante variadas, a Caixa Escolar significava um meio de fazer com que a comunidade participasse efetivamente na formação de seus cidadãos, de seus futuros trabalhadores e na diminuição do número de analfabetos.

Firmino Costa, nos dois primeiros anos de trabalho no Grupo Escolar, pretendeu despertar o povo para essa responsabilidade, e se, no começo de 1908, o seu artigo denominado "Em prol da instrução" não surtiu o efeito por ele esperado, no mês de junho do mesmo ano ele escreveu outro artigo, que veio com um título em destaque na primeira página do boletim Vida Escolar: "Um appello". 
Nesse artigo, primeiramente, o diretor destacou a importância do "bem comum", que deveria unir o povo em busca dos interesses sociais. O egoísmo seria substituído pelo altruísmo, para promover o bem próprio e familiar e, consequentemente, viria o progresso social. Cuidar da cidade, segundo seu parecer, era cuidar do próprio lugar onde se vive, daí a necessidade de buscar e construir também o "bem publico".

A construção do bem público se daria mediante o desprendimento individual, do qual todos deveriam participar solidariamente, para que o progresso fosse desfrutado de forma coletiva e individualizada.

Firmino Costa, preocupado em formar uma opinião pública, a favor de um item constitutivo de sua época, a Caixa Escolar, envolve a sociedade lavrense, comprometendo-a pela sua construção. Para Faria Filho, a edificação de uma cultura urbana e escolar é fundamentada pelos educadores dessa época com proposições em prol de uma homogeneização cultural, permeada de diversidades materiais e sociais dos indivíduos, num campo, em que os elementos fundamentais da sociedade são repletos de tensões permanentes: a propriedade, o indivíduo e a razão.

Cultura escolar e cultura urbana são elaboradas, nessa época, compenetradas por um pensamento individual liberal, como também o pensamento republicano do século XIX, por isso, a defesa em prol das crianças pobres do Grupo Escolar não tinha somente um vínculo com questões sociais e coletivas, mas, se resolvida, atenderia às necessidades individualizantes de "estabilidade do progresso lavrense." (VIDA ESCOLAR, p. 1, 15 jun. 1908)

Para Firmino Costa, essa participação do povo com doações representava o termômetro de medição, que mostrava a aceitação da nova instituição - o Grupo Escolar.

O dinheiro arrecadado não era utilizado somente para ajudar diretamente os alunos pobres, mas prestava-se também para financiar materiais para o ensino. Com pouca verba, em 1910, uma quermesse, ou tômbola, foi realizada para arrecadar fundos para a Caixa Escolar, sendo noticiada no Jornal Minas Geraes, como propaganda para que os outros Grupos Escolares seguissem o exemplo.

Com o propósito de demonstrar o enlaçamento existente entre o escolar e o urbano, as duas citações apresentam dois momentos: o povo indo até o Grupo 
Escolar, fazendo doações, e o Grupo indo para a cidade, fora de seus muros, arrecadando verbas para a Caixa Escolar. Um entrelaçamento de mão dupla, que mostra o econômico como um dos fatores importantes na construção dessa nova cultura escolar.

Depois de muitas campanhas e propagandas difundindo a importância e a responsabilidade da comunidade em ajudar a Caixa Escolar, o diretor, seguro do retorno que estava tendo de várias contribuições de diferentes tipos, utilizou um recurso próprio da comunidade, as quermesses - festas geralmente utilizadas pelas igrejas em comemoração dos santos padroeiros - e lança-se na praça da cidade, lugar onde os alunos brincavam, as famílias passeavam e as pessoas se encontravam. A constituição dessa relação, no parecer de Faria Filho, ajuda-nos a compreender o momento de afirmação de uma instituição social, num processo de vários significados, a "buscar entender como a instituição escolar inscreve-se constituindo e sendo constituída - nas teias de relações urbanas" (FARIA FILHO, 2002, p. 5).

Em 1911, o secretário Delfim Moreira, percebendo que a criação das Caixas Escolares nos Grupos Escolares não atingiu o desenvolvimento que se desejava, ele convocou professores e diretores dos Grupos Escolares para reorganizar o funcionamento das Caixas Escolares, tornando-as uma instituição local que deveria ter estatutos próprios.

Em 1911, Firmino Costa apresentava ao povo a necessidade de se criar a Caixa Escolar, sendo que primeiramente retomou o discurso de inauguração do Grupo Escolar, pronunciado em 1907, lembrando que disse que "o povo lavrense comprehenderá que é delle o Grupo Escolar e tratará este estabelecimento como uma de suas mais valiosas propriedades" (FOLHA DE LAVRAS, p. 1, 28 set. 1911). Depois de reconhecer a participação do povo no que considerava valorização e engrandecimento do Grupo Escolar, que a seu ver conseguiu conquistar a confiança da sociedade, progredir e desenvolver-se amplamente, Firmino Costa apresentou um problema que os alunos do Grupo vinham enfrentando:

Entre os alumnos do Grupo há muitos que não podem comprar livros, cadernos e outros utensilios escolares, muitos que necessitam de roupa, de alimentos e de remedios: a solução única é fornecerIhes a sociedade lavrense taes meios, com que elles vão preparar-se 
para serem elementos uteis á cidade. (FOLHA DE LAVRAS, 28 set. 1911, p. 1)

Investir financeiramente no futuro das crianças pobres era garantia de formação de jovens úteis à sociedade, o que consequentemente significaria progresso para a cidade. Para convencer a comunidade da importância de auxiliar esses alunos pobres, Firmino Costa dizia que o empréstimo era pago, amortizado, com a educação, e completava: "Ora, quem melhor do que os meninos, parte de nós mesmos, merecerá tão affectuosa prova de confiança, quem mais do que elles offerecerá garantias de transformar em fructos de civilização o adeantamento hoje recebido?"

Em 21 de janeiro de 1912, o presidente da Câmara Municipal, presidiu uma reunião no salão do Fórum, juntamente com 27 dos 105 sócios fundadores, onde foram eleitos o presidente, os fiscais e o tesoureiro, todos sem vínculo direto com o Grupo Escolar.

Em 1915, o Diário de Lavras (10 fev. 1915), ao apresentar um resumo do movimento anual do Grupo Escolar, registrou um significativo aumento da frequência escolar: "A freqüência de 1914 comparada com a de 1907, anno da installação do Grupo, offerece um accrescimo de 93\%". Se o segundo momento de criação da Caixa Escolar tinha como objetivo manter a freqüência dos alunos, os dados acima mostram que tal objetivo estava sendo atingido, havendo até um aumento na receita: "A caixa escolar "Dr. Augusto Silva, rendeu a importancia de 2:352\$412 e dispendeu a de 1:563\$780, verificando-se um saldo a favor da caixa, de 788\$632." (DIÁRIO DE LAVRAS, 10 fev. 1915)

Alguns exemplos mostram como o dinheiro da Caixa Escolar era aplicado: "A assistencia escolar foi representada do modo seguinte: livros fornecidos 253; materiaes didacticos; merenda diaria para 120 alumnos; vistuarios, 145; canecas para agua, 150; cortes de cabello, 198; applicação de remedios; manutenção de um telephone e a conservação de uma cama preparada para o caso de doença."

Vago, analisando esse segundo momento de reinstituição das Caixas Escolares, percebeu que ajudar as crianças pobres, dando-Ihes condições materiais e higiênicas para que frequentassem a escola, constituía também um "recurso sanitário" (VAGO, 2002, p. 159) da cultura escolar da época e tomou como 
ilustração outro recurso que Firmino Costa utilizou para arrecadar fundos para a Caixa Escolar, colocando cofres nos pontos comerciais.

Em 1916, os cofres também foram colocados nas salas de aula, e os alunos incentivados a fazer doações. Quadros de propaganda foram afixados, com os dizeres: "Como hei de festejar o dia de meus annos? Dando á Caixa Escolar uma esmola, ainda que seja pequenina." (COSTA, 1916, p. 48)

A Caixa Escolar era considerada pelo diretor uma "sociedade de caridosa civilização", pois a cidade estava dando condições para que os alunos pobres fossem estudar e não abandonassem a escola por falta de recursos. O retorno seria uma população mais culta, com a ignorância extinta, pois por meio dela é que surgiam todas as espécies de vícios, como a bebida, o fumo, os jogos e a vagabundagem.

Em 1917, o décimo relatório anual do Grupo Escolar de Lavras enviado à Secretaria do Interior apresentava as seguintes fontes de renda da Caixa Escolar: "[...] mensalidades dos socios; auxilio da Camara Municipal; sessão do Cinema Internacional; donativos; cofres escolares; gratificação de professores; tombola escolar [...]. (COSTA, 1917, p. 8)

As verbas eram aplicadas nas seguintes necessidades: "[...] merenda aos alumnos pobres; vestuario para os mesmos; material didactico; utensilios de hygiene; premio escolar; despesas com o expediente." (COSTA, 1917, p. 8)

Os inspetores escolares, ao mesmo tempo em que estavam imbuídos da função de fiscalizar, enviavam à Secretaria do Interior seus relatórios, depois das visitas aos Grupos Escolares. Muitos desses relatórios traziam pareceres e sugestões dos inspetores, que não se esquivavam em fazer uma análise da situação do ensino que eles percebiam nos Grupos Escolares.

Foi nesse contexto que o inspetor Cândido Prado, em seu relatório de 1917, apresentou sua preocupação com o elevado número de crianças analfabetas ainda existentes, citando três fatores que, a seu ver, eram causadores de tal fato: "pobresa ou indigencia; indifferentismo dos paes ou responsaveis; falta de escolas em muitas localidades." (SECRETARIA DO INTERIOR, SI 3790, 1918)

Para os três problemas, Cândido Prado apresentou também três soluções: "Fundando-se "Caixa Escolar"; instituindo-se Conferencias contra o analphabetismo; 
creando-se escolas em todos os povoados." (SECRETARIA DO INTERIOR, SI 3790, 1918)

O inspetor citou, então, Lavras como exemplo de cidade em que a propagação da instrução popular era concretizada e onde não existiam analfabetos. O analfabetismo foi designado pelo inspetor como um "maligno cancro social", que precisava ser combatido com remédios certos. Interessante perceber que Cynthia Greive (VEIGA, 2002, p. 277) utiliza de uma fonte datada de 1892, na qual consta a palavra "cancro". Essa relação demonstra que o analfabetismo no século XIX e início do XX era visto como responsável pela ignorância do povo, uma doença que se alastrava, principalmente entre os pobres, e que precisava ser tratada e extinta.

Vários recursos pedagógicos e didáticos foram criados com o objetivo de aumentar a frequência, auxiliar o professor na tarefa de ensinar e assegurar uma boa disciplina.

\section{CONSIDERAÇÕES FINAIS}

As práticas pedagógicas estrategicamente construídas por Firmino Costa para fundamentar a obrigatoriedade de ensino e garantir um índice aplausível de frequentadores nos bancos escolares, presta-se como fundamento de análise das políticas públicas educacionais na contemporaneidade.

O número de escolas na atualidade aumentou em comparação às primeiras décadas do século $\mathrm{XX}$, o número de analfabetos também diminuiu mas ainda não há uma baixa qualidade de ensino nos níveis fundamentais e médio que, mesmo com uma expressiva frequência, tem produzido analfabetos funcionais. A lei da obrigatoriedade de ensino é colocada em prática, com o respaldo de instituições que foram criadas para legitimá-la: o conselho tutelar que trabalha conjuntamente com o juizado de menores.

As políticas públicas educacionais ainda são necessárias em pleno século XXI. A bolsa família, num viés próximo à caixa escolar instituída pelos Grupos Escolares a mais de cem anos atrás, indica que muito ainda tem que ser feito para garantir a permanência dos alunos nos bancos escolares, principalmente no Ensino Médio onde a evasão é expressiva. 
No convencimento da implantação de uma nova cultura que surgiu com o Grupo Escolar, vários foram os obstáculos, principalmente aqueles voltados para a sua importância e valor social. Na década de 30 do século $X X$ a iniciativa republicana de universalização da escola pública se encontrava estagnada e a escrita do 'Manifesto dos Pioneiros' em 1932 defendia uma escola universal, pública e gratuita, de qualidade e laica.

Essa mesma bandeira ainda se faz pertinente, principalmente quando no século XXI as propostas republicanas de reforma econômica comprometem o investimento financeiro na educação e na saúde por vinte anos, desrespeitando o Plano Nacional de Educação e alterando a Lei de Diretrizes e Bases da Educação sem a abertura de canais de debate e discussão para a sociedade.

Oxalá possamos desfrutar novos e melhores horizontes para a educação pública no Brasil.

\section{REFERÊNCIAS BIBLIOGRÁFICAS}

COSTA, Firmino. O ensino popular. Belo Horizonte: Imprensa Oficial, 1913. 108p.

Vida Escolar. V. 2, 15 nov. 1908.

A educação popular. Belo Horizonte, Imprensa Oficial, 1918. 22p.

FARIA FILHO, Luciano Mendes de. Dos pardieiros aos palácios: cultura escolar e urbana em Belo Horizonte na Primeira República. Passo Fundo: UPF, 2000.

Escolarização, culturas e práticas escolares no Brasil: elementos teórico-metodológicos de um programa de pesquisa. Impresso, 2000, 20 p.

; VIDAL, Diana G. Os tempos e os espaços escolares no processo de institucionalização da escola primária no Brasil. Revista Brasileira de Educação, Belo Horizonte, 14, p. 19-34, 2000.

República, trabalho e educação: a experiência do Instituto João Pinheiro 1909/1934. Bragança Paulista: Editora da Universidade São Francisco, 2001.

. Cultura escolar e cultura urbana: perspectivas de pesquisa em história da educação. In: II CONGRESSO BRASILEIRO DE HISTÓRIA DA EDUCAÇÃO, 2, 2002, Natal. Anais... Natal Núcleo de Arte e Cultura da UFRN, 2002. CD- ROM.

HANDAN, Juliana Cesário; PEREIRA, Jardel da Costa. "A vida há de ser uma educação permanente": a educação entretecida na vida do educador Firmino Costa. In: FARIA FILHO, Luciano Mendes. INÁCIO, Marcilaine Soares. (Orgs.). Políticos, 
literatos, professoras, intelectuais: o debate público sobre educação em Minas Gerais. Belo Horizonte: Mazza Edições, 2009.

MINAS GERAIS. Arquivo Público Mineiro. Relatórios dos diretores de grupos escolares. 1905/ 1907/ 1913/ 1918.

Arquivo Público Mineiro. Relatórios dos inspetores técnicos do ensino. 1905/1913/1917/1918.

. Leis, decretos, etc. Lei n. 434, de 28 de setembro de 1906. Autoriza a reforma do ensino público. [s.n.t.].

Governo do Estado. Administração João Pinheiro da Silva. Decreto no. 1.960, de 16 de dezembo de 1906. Regulamento do ensino primário e normal.

PEREIRA, Jardel Costa. Grupo Escolar de Lavras: produzindo uma instituição modelar em Minas Gerais (1907-1918). Dissertação (Mestrado em Educação) Faculdade de Educação, Universidade Federal de Minas Gerais, Belo Horizonte, 2005.

SOUZA, Rosa Fátima de. Templos de civilização: a implantação da Escola Primária Graduada no Estado de São Paulo (1890-1910). São Paulo: Fundação Editora da UNESP, 1998.

SOUZA, Rosa Fátima de; VALDEMARIN, Vera Teresa; ALMEIDA, Jane Soares de. O legado educacional do século XIX. Araraquara: Fundação Editora da UNESP, 1998.

VAGO, Tarcísio Mauro Vago. Cultura escolar, cultivo de corpos: educação physica e gymnastica como práticas constitutivas dos corpos de crianças no ensino público primário de Belo Horizonte (1906-1920). Bragança Paulista: EDUSF, 2002.

VEIGA, Cynthia Greive. FARIA FILHO, Luciano M. Belo Horizonte: a escola e os Processos educativos no movimento da cidade. Varia História, Departamento de História da UFMG, 18, p. 203-224, nov. 1997.

VEIGA, Cynthia Greive. Cidadania e educação na trama da cidade: a construção de Belo Horizonte em fins do século XIX. Bragança Paulista: EDUSF, 2002. 